
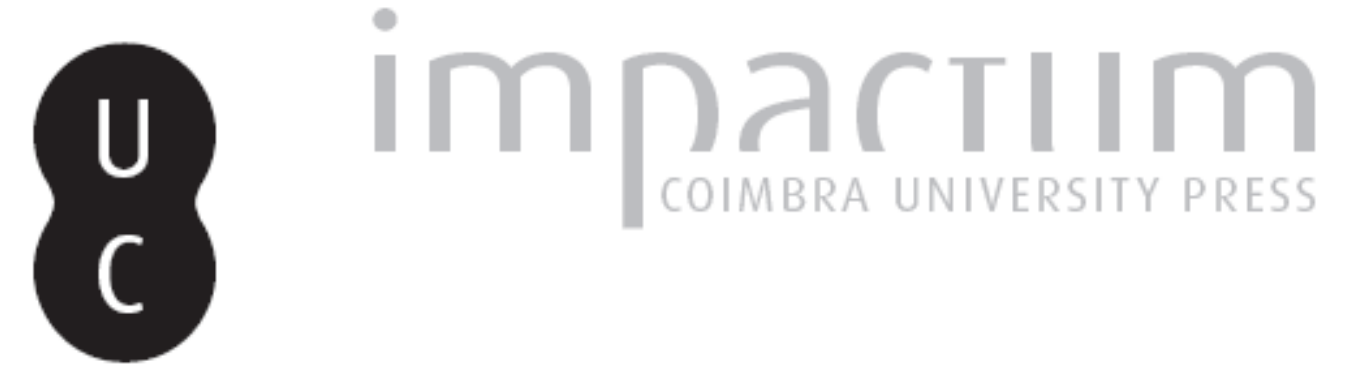

\title{
Atopia em Pierre Hadot (parte 1)
}

Autor(es): $\quad$ Almeida Júnior, George Matias de

Publicado por: Annablume Clássica; Imprensa da Universidade de Coimbra

URL persistente:

URI:http://hdl.handle.net/10316.2/39283

DOI:

DOI:http://dx.doi.org/10.14195/1984-249X_18_10

Accessed : $\quad$ 26-Apr-2023 12:00:39

A navegação consulta e descarregamento dos títulos inseridos nas Bibliotecas Digitais UC Digitalis, UC Pombalina e UC Impactum, pressupõem a aceitação plena e sem reservas dos Termos e Condições de Uso destas Bibliotecas Digitais, disponíveis em https://digitalis.uc.pt/pt-pt/termos.

Conforme exposto nos referidos Termos e Condições de Uso, o descarregamento de títulos de acesso restrito requer uma licença válida de autorização devendo o utilizador aceder ao(s) documento(s) a partir de um endereço de IP da instituição detentora da supramencionada licença.

Ao utilizador é apenas permitido o descarregamento para uso pessoal, pelo que o emprego do(s) título(s) descarregado(s) para outro fim, designadamente comercial, carece de autorização do respetivo autor ou editor da obra.

Na medida em que todas as obras da UC Digitalis se encontram protegidas pelo Código do Direito de Autor e Direitos Conexos e demais legislação aplicável, toda a cópia, parcial ou total, deste documento, nos casos em que é legalmente admitida, deverá conter ou fazer-se acompanhar por este aviso.

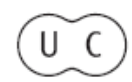




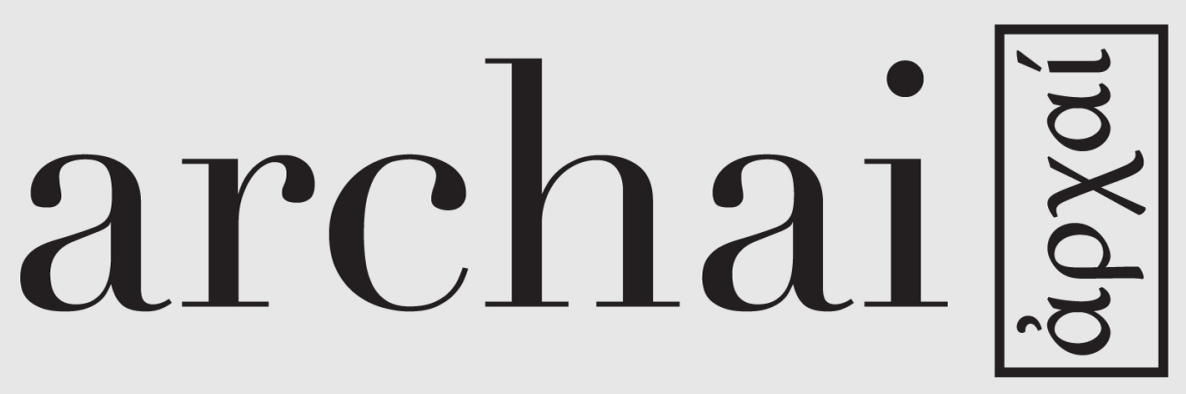

Revista sobre as origens do pensamento ocidental Journal on the Origins of Western Thought

18 | sep.-dec. 2016 


\section{Atopia em Pierre Hadot (PARTE 1)}

archai圈

n 18 , sept.-dec. 2016

\section{Atopia in Pierre Hadot (part 1)}

ALMEIDA JÚNIOR, G. M. (2016). Atopia em Pierre Hadot. Archai, $\mathrm{n}^{\mathrm{o}} 18$, sept.- dec., p. 347-386.

DOI: http://dx.doi.org/10.14195/1984-249X_18_10

RESUMO: Vamos apresentar alguns aspectos da concepção de Pierre Hadot da filosofia antiga compreendida como "modo de vida" e exercida através dos chamados "exercícios espirituais", a tese principal do autor nas obras que nos propomos a analisar. A partir dessa perspectiva, destacamos primeiramente a importância da figura de Sócrates na constituição do ponto de vista de Hadot, e, sobretudo, como o autor mobiliza a noção de atopia, entendida em largos traços como a "estranheza" (étrangeté) do filósofo no mundo humano, derivada do Sócrates dos diálogos de Platão. Em segundo lugar, apresentamos os sentidos dessa estranheza, além de destacar suas origens, algumas de suas possibilidades conceituais assim como algumas de suas aporias. Supomos ainda que a reflexão de Hadot, além de pôr em relevo 


\section{archai圈}

$\mathrm{n}^{\mathrm{o}} 18$, sept.-dec. 2016

G. M. Almeida Júnior, 'Atopia em Pierre Hadot', p. 347-386 a questão sobre a atopia, parece ser ela mesma atópica, num sentido que será indicado.

Palavras-chave: atopia; Sócrates; Pierre Hadot; personalidade; modos de vida.

ABSTRACT: We will present some aspects of Pierre Hadot's conception of ancient philosophy understood as "way of life" and practised through the so called "spiritual exercises", the author's main thesis in the works which we propose to evaluate. From this perspective, we firstly emphasize the relevance of the figure of Socrates in the constitution of Hadot's point of view and, above all, how the author mobilises the notion of atopia, which can be broadly understood as the philosopher's strangeness (étrangeté) in the human world, derived from the figure of Socrates in Plato's dialogues. Secondly, we present the meanings of this strangeness, pointing out its origins, some of its conceptual possibilities as well as some of the aporiai which lie in Hadot's thesis. We also believe that Hadot's reflection, besides bringing out the question of atopia, seems to be atopic itself in a sense that it will be pointed out.

Keywords: atopia; Socrates; Pierre Hadot; personality; ways of life. 


\section{INTRODUÇÃOO ${ }^{1}$}

Este artigo tem por objetivo principal mostrar como surge a questão da atopia na obra de Pierre Hadot, que pode ser definida em linhas gerais como a "estranheza" própria do filósofo. Procuramos mostrar o que é, de onde emerge e quais são as implicações dessa estranheza na obra do pensador francês, tendo em vista a sua principal tese da filosofia antiga como modo de vida, realizada através dos denominados exercícios espirituais. Para isso, o artigo a) procura mostrar que Hadot radica sua mais conhecida tese na filosofia de Sócrates e b) analisa como o autor francês reconstrói a figura socrática dando particular ênfase à noção de atopia. A partir daí, avaliamos como c) Hadot estende a atopia peculiar de Sócrates para dar conta do fenômeno singular da filosofia antiga de maneira geral e, enfim, d) discutimos se e de que maneira a própria obra de Hadot pode conter uma manifestação dessa "estranheza", que seria então não apenas uma marca própria da filosofia antiga, mas da filosofia simplesmente, a de Hadot em particular. Devido à extensão deste artigo, ele foi dividido em duas partes: a primeira trata das alíneas "a" e "b" acima enunciadas, enquanto a segunda parte, a ser publicada posteriormente, tratará das alíneas "c" e "d".

\section{Sócrates e A Filosofia COMO MODO DE VIDA}

Dificilmente seria possível oferecer um panorama justo das teses de um autor como Pierre Hadot, que dedicou a maturidade de sua carreira a empreender uma leitura da filosofia antiga de maneira abrangente, envolvendo seu percurso histórico e a sucessão de

\section{archai萇}

n 18 , sept.-dec. 2016

G. M. Almeida Júnior, 'Atopia em Pierre Hadot', p. 347-386 


\section{archai圈}

$\mathrm{n}^{\mathrm{o}} 18$, sept.-dec. 2016

G. M. Almeida Júnior, 'Atopia em Pierre Hadot', p. 347-386 suas escolas, onde apenas a filosofia "pré-socrática" não ganha destaque. A lacuna concernente aos pré-socráticos na principal tese de Hadot parece ser explicável pelo ponto de partida que o estudioso assume, qual seja, o de tomar Sócrates como a primeira e a principal figura representativa da compreensão e prática da filosofia como modo de vida, tal como vemos na seguinte citação:

Em primeiro lugar, ao menos desde Sócrates, a opção por um modo de vida não se situa no fim do processo da atividade filosófica, como uma espécie de apêndice acessório, mas, bem ao contrário, na origem, em uma complexa interação entre a reação crítica a outras atitudes existenciais, a visão global de certa maneira de viver e ver o mundo, e a própria decisão voluntária; e essa opção determina até certo ponto a doutrina e o modo de ensinamento dessa doutrina. (HADOT, 2010, p. 17, grifos nossos).

Ao longo do livro "O que é a filosofia antiga?", bem como nos textos de Hadot posteriores aos anos 70, podemos perceber um interesse visceral do autor francês pela figura de Sócrates, que se destaca entre as diversas referências filosóficas presentes em suas obras como um ponto de clivagem na história da filosofia grega, além de ser uma influência importante na concepção mais ampla que Hadot elabora acerca da filosofia ou do 'filosofar'. Pode-se dizer que o autor, nesse ponto, segue uma tradição bastante antiga, reportada por Cícero (Tusculanas 5.4), que apresenta Sócrates como um divisor de águas em sua tradição, por ter feito a filosofia descer do céu à terra, retirando-a da especulação naturalista e voltando-a para o aprendizado do bem e do mal, para as cidades, as casas e os costumes. 
Hadot não menciona esse famigerado comentário de Cícero nos textos aqui visados, mas podemos dizer que ele segue a concepção ciceroniana de Sócrates como o pai da ética, como o primeiro filósofo a pôr a "vida" (bios) enquanto sua principal pergunta, ainda que Hadot introduza elementos peculiares nessa maneira comum de descrever o lugar de Sócrates na tradição antiga (e ulterior) ${ }^{2}$.

Para Hadot, mais do que iniciar uma tradição discursiva filosófica sobre o problema teórico em torno dos bioi, Sócrates representaria uma exceção em relação aos demais filósofos, anteriores e posteriores, pois no seu caso seria impossível separar seu discurso filosófico de sua vida (e morte): "Pode-se separar o discurso de Sócrates da vida e da morte de Sócrates?" (HADOT, 2010, p. 21). Uma das mais notáveis singularidades de Sócrates, a rigorosa inseparabilidade entre seu discurso e sua vida, é relembrada por Hadot imediatamente antes de ele oferecer uma definição esclarecedora da noção de "exercícios espirituais":

Uma noção aparecerá frequentemente nas páginas que se seguem, a de exercícios espirituais. Designo por esse termo as práticas, que podem ser de ordem física, como o regime alimentar; discursiva, como o diálogo e a meditação; ou intuitiva, como a contemplação, mas que são todas destinadas a operar modificação e transformação no sujeito que as pratica. (HADOT, 2010, p. 21).

Sócrates representaria da maneira mais clara o fim último dos exercícios espirituais, oferecendo-se como o modelo mais eloquente para mostrar como a filosofia antiga é diferente porque nela o discurso filosófico

\section{archai嚎}

n 18 , sept.-dec. 2016

G. M. Almeida Júnior, 'Atopia em Pierre Hadot', p. 347-386 


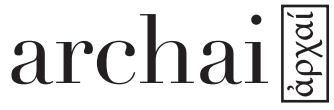

no 18 , sept.-dec. 2016

G. M. Almeida Júnior, 'Atopia em Pierre Hadot', p. 347-386 não se aparta da vida, ou mais precisamente, porque na filosofia antiga o discurso filosófico não tem autonomia num plano teórico separado, podendo ser compreendido apenas no contexto de uma opção existencial, não apenas como junto ao bios daquele que pratica a filosofia, mas sendo determinado pela vida. Sócrates seria o exemplo maior quando se trata de conceber uma filosofia definida por seu valor transformativo, pela ênfase na vida e no vivido, por estar vinculada à modificação do sujeito que a pratica, como diz o texto acima citado, mas também por estar dirigida à transformação integral da "personalidade", como Hadot diz em outros lugares (1987, p. 14, 20).

De maneira geral, em mais de uma obra Hadot insiste no papel de Sócrates como o fundador e um dos principais expoentes da concepção da filosofia como maneira de viver (1987, p. 29-37; p. 77-108; p. 221; 2009 , p. 121-124; 2010, p. 47-68). Não seria exagerado dizer, portanto, que um dos principais fios condutores da concepção da filosofia antiga segundo Hadot está calcado numa certa visão que o autor faz da filosofia socrática, isto é, do modo de vida de Sócrates. Entretanto, se Sócrates é uma das origens, senão a "Origem" do principal conceito que Hadot desenvolve em sua leitura da filosofia antiga, acabamos nos deparando com o conhecido "problema de Sócrates", e assim corremos o risco de atingir o ponto oposto ao que esperamos, confundindo mais as coisas, ao invés de lançar alguma luz num aspecto singular da obra do pensador francês, que parece decisivo tanto para sua concepção histórica da filosofia antiga quanto para sua reflexão sobre a prática da filosofia nos dias de hoje. 
Hadot manifesta consciência dos paradoxos que se põem na medida em que o socratismo aparece como um fenômeno bem influente na história da filosofia, ainda que, ao mesmo tempo, seja difícil ou senão impossível conhecer o que dizia ou quem realmente era Sócrates. Diante dos poucos dados realmente confiáveis sobre Sócrates, quais sejam, a se seguir Olof Gigon $^{3}$, uma das referências explicitadas e endossadas por Hadot (2012, p.7, n.1), os de que existiu um ateniense de nome Sócrates que foi condenado à morte em 399 a.C., que praticou uma forma de saber pela qual ficou conhecido, sem ter deixado qualquer obra escrita, e que se poderia saber muito pouco além disso, Hadot tenta reconstruir o filósofo paradigmático em sua reflexão sobre os exercícios espirituais, acentuando que ele pode ser comparado a um "mito" para a tradição ocidental, sendo relevante mesmo para o nascimento do pensamento contemporâneo (2012, p. 8).

Assim, fica claro que Sócrates (personagem) tem uma função vital na tese mais contundente de Hadot, o que nos induz a avançar mais no entendimento que $o$ autor francês tem da figura modelar da filosofia como modo de vida. Como veremos abaixo, a imagem que Hadot faz do filósofo é basicamente fundada na concepção platônica, com um destaque especial para o Banquete, sobretudo para o mito de Eros contado por Diotima, bem como para o famoso discurso que Alcibíades elabora para tentar dar conta justamente da natureza atópica de Sócrates.

\section{A atopia de Sócrates segundo Hadot}

A figura de Sócrates é fundamental para Hadot e para a formulação de sua concepção da filosofia

\section{archai圈}

n 18 , sept.-dec. 2016

G. M. Almeida Júnior, 'Atopia em Pierre Hadot', p. 347-386 


\section{archai圈}

no 18 , sept.-dec. 2016

G. M. Almeida Júnior, 'Atopia em Pierre Hadot', p. 347-386 antiga como modo de vida. Mas de que maneira? Quem é o Sócrates de Hadot? Nesta seção, procuramos detalhar a complexa figuração que Hadot faz de Sócrates, dando ênfase especial à atopia socrática, isto é, à "estranheza" e à originalidade de uma "personalidade incomparável”, temas que o autor francês reelabora a partir da concepção de filosofia tal como delineada no Banquete de Platão, mais especificamente a partir dos discursos de Diotima sobre Eros e de Alcibíades sobre a atopia de Sócrates (Smp. 215a2; 221d2). Dividimos esta seção em dois tópicos: o primeiro deles é dedicado aos conceitos principais que Hadot utiliza para estabelecer sua imagem de Sócrates, e o segundo destaca como o autor francês identifica e explora o tema da atopia socrática.

\subsection{As MÁsCARAS SOCRÁTICAS}

Como dissemos acima, Hadot se coloca na esteira de Gigon e assume um ceticismo em relação à historicidade de Sócrates, admitindo que sua preocupação não é a de reconstituir o Sócrates histórico, já que isto, além de ser quase impossível, não seria necessário, ou, tal como exclama Hadot, "pouco importa!" (HADOT, 2012, p. 7). O que importa a Hadot é a "figura", ou o "mito" socrático, são as "máscaras" que o fenômeno Sócrates assumiu nos percursos históricos e espirituais da filosofia no Ocidente ${ }^{4}$.

A principal análise que o autor dedica a Sócrates pode ser encontrada no ensaio "La figure de Socrate", uma conferência proferida em 1974, depois integrada ao livro Exercices spirituels et philosophie antique (1987, p. 77-116), e ainda, publicada posteriormente com o título de Éloge de Socrate $(1998)^{5}$, com pequenas 
modificações. Neste ensaio, o autor identifica e avalia as máscaras postas sobre Sócrates nas obras de Platão, Kierkegaard e Nietzsche, notando os paradoxos do filósofo irônico e "inclassificável" (inclassable). Dessa conferência surge o essencial da apropriação de Hadot em torno da figura de Sócrates, que será repetido em outras obras do autor, com algumas nuanças que serão notadas mais adiante.

Para apresentar as linhas gerais do Elogio de Sócrates, é conveniente antes destacar alguns pontos do texto platônico mais decisivo para as reflexões de Hadot, o Banquete, que possui uma importância especial para o autor francês em sua concepção da filosofia antiga. De toda a riqueza literária e filosófica do diálogo platônico, Hadot destaca alguns dos principais temas do discurso atribuído à sacerdotisa Diotima, em que Sócrates narra um aprendizado fundamental sobre as coisas do amor. Segundo Diotima, Eros não seria propriamente um deus, mas, por ser filho de Poros e Penia, seria na verdade um daimon, um intermediário entre deuses e homens, e, enquanto tal, em síntese, seria um ser ao mesmo tempo pleno de recursos e carente. Hadot retoma também o discurso de Alcibíades, no qual se afirma a falta de parâmetros para classificar Sócrates, que não teria par entre os homens, podendo ser comparado tão-somente aos Sátiros e aos Silenos (Smp. 215a-b; 221c-d).

Do discurso de Diotima Hadot ressalta particularmente a concepção da filosofia como "Philo-sophia", ou seja, amor à sabedoria, constatando o caráter transcendente e não inteiramente racional da sophia, já que, tal como ensina a sacerdotisa, a sabedoria é um atributo exclusivo dos deuses (Smp. 203a). Desse

\section{archai蒡}

n 18 , sept.-dec. 2016

G. M. Almeida Júnior, 'Atopia em Pierre Hadot', p. 347-386 


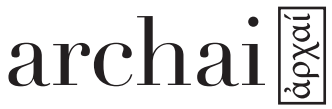

no 18 , sept.-dec. 2016

G. M. Almeida Júnior, 'Atopia em Pierre Hadot', p. 347-386 modo, o filósofo, à semelhança de Eros, seria uma espécie de "intermediário", posicionado a meio caminho entre a sabedoria (divina) e a ignorância (humana) e envolvido na busca de algo que não pode alcançar definitivamente, mas que também não pode deixar de procurar, devido a um intenso desejo provocado pela consciência e sentimento de privação (justamente o que Sócrates promove com suas atitudes discursivas e eróticas). Por causa desse amor à sabedoria, uma "norma transcendente", o filósofo acaba por vivenciar a situação insólita de não estar nem inteiramente dentro do mundo, e nem inteiramente fora.

Do discurso de Alcibíades, Hadot enfatiza a imagem 'silênica' de Sócrates, todo o erotismo e a ironia de seu comportamento, além da atopia que melhor define a situação desse ser "inclassificável" - pois Sócrates não é nem um homem como os outros e nem um deus, não é um sábio e tampouco um ignorante- e "estranho", porque cotidianamente devotado a buscar uma sabedoria estrangeira ao mundo dos homens.

A partir da composição entre o discurso de Diotima e o discurso de Alcibíades, Hadot se volta para a "ironia", o conceito essencial em sua leitura e um dos aspectos historicamente mais cruciais para a reconstrução da figura "desconcertante, ambígua e inquietante" de Sócrates. Na esteira das concepções antigas de Platão, Aristóteles ${ }^{6}$, Teofrasto ${ }^{7}$ e Cícero $^{8}$, Hadot toma a ironia como uma "atitude psicológica na qual o indivíduo busca parecer inferior ao que ele é: ele se autodeprecia" (2012, p. 16). Hadot relaciona a ironia ao fingimento, à inversão de valores e à refinada dissimulação socrática: Sócrates diz uma coisa e pensa outra; ele finge a ignorância e a impudência, finge 
assumir o ponto de vista de seu interlocutor, finge estar enamorado, finge ser banal, até mesmo sua aparência física engana, e tudo isso com sinuosos propósitos ulteriores, sobretudo o de fazer surgir nos homens a consciência de que eles não são sábios e convertê-los ao cuidado de si.

A ironia funda outro aspecto fundamental do socratismo, o jogo de máscaras que ele provoca, na medida em que os testemunhos que possuímos sobre Sócrates "o ocultam mais do que o revelam a nós", ao mesmo tempo em que "Sócrates sempre serviu de máscara aos que falaram e falam sobre ele" (Hadot, 2012 , p. 10). Ironicamente, esse jogo de máscaras encobre o caráter de Sócrates e, não obstante, acaba por revelar uma verdade fundamental, a condição de privação do saber e da plenitude do ser da qual Sócrates procura tornar os homens conscientes. Essa revelação, contudo, não ocorre de maneira direta, mas pela aporia, pelo choque e pela provocação, enfim, pela ironia e por uma experiência de comunicação consciente dos limites da linguagem e da racionalidade. Seja em sua faceta discursiva, seja em sua faceta erótica - Hadot destaca a conjunção destes dois aspectos - a ironia presente nos discursos e nas atitudes de Sócrates opera de modo a produzir num interlocutor "uma consciência desdobrada que sente apaixonadamente que não é o que deveria ser" (Hadot, 2012, p. 35).

Além de Platão e a concepção de ironia herdada dos autores antigos, sobretudo de Cícero, Hadot evoca dois pensadores que foram capazes de perceber a real potência da dissimulação e o poder erótico e sedutor do jogo provocado por Sócrates: Kierkegaard e Nietzsche. Estes "dois grandes socráticos”, como nos diz

\section{archai萇}

n 18 , sept.-dec. 2016

G. M. Almeida Júnior, 'Atopia em Pierre Hadot', p. 347-386 


\section{archai圈}

no 18 , sept.-dec. 2016

G. M. Almeida Júnior, 'Atopia em Pierre Hadot', p. 347-386
Hadot (2012, p. 7), entenderam a essência da ironia, posto que, segundo o termo nietzscheano apropriado por Hadot, eles se engajaram na "semiótica" de Sócrates (2012, p. 12), o que quer dizer que eles se esforçaram por compreender o sentido da filosofia socrática (ou da personalidade de Sócrates), e mais que isso, quer dizer que procuraram criar uma identidade com essa estranha figura da filosofia, entranhando-se nas profundezas ocultas pelas máscaras que teriam sido postas sobre Sócrates, inclusive por ele próprio. Desse engajamento junto a Sócrates, nem que seja para criticá-lo, surgiram filosofias originais, ou talvez pessoais, que muito influenciaram a concepção filosófica de Hadot.

Kierkegaard e Nietzsche jogaram com as três máscaras que melhor definiriam o sentido irônico das práticas socráticas, todas elas elaboradas no Banquete de Platão: a de Sileno, a de Eros e a de Dioniso. O tratamento dessas três "máscaras" constitui o cerne da apropriação de Sócrates por Hadot e corresponde às três seções do Elogio de Sócrates.

A máscara do "Sileno", tratada nas páginas 8-16 do ensaio em questão, parte do fingimento sugerido pela própria fisionomia de Sócrates, que no limite acaba por revelar que tudo nele é uma fachada que oculta algo de mais profundo- veremos que se trata de uma filosofia irredutível a um sistema teórico e a uma atitude professoral, que se radica antes numa atitude existencial e num apelo à consciência do que na elaboração e difusão de uma doutrina. Nas palavras de Alcibíades, a aparência de Sócrates assemelha-se à dos Sátiros e aos Silenos, esses seres bizarros, lascivos e bufões, que representavam um estado pura- 
mente natural, anterior à cultura e a civilização, e que, portanto, além da feiura, sugeriam uma imagem que colocava em questão os valores e as atitudes de Sócrates perante a normalidade e as expectativas de comportamento estabelecidas. Por ser como um Sátiro, Sócrates encanta, estranha, desorienta e desconcerta. No entanto, Alcibíades lembra também que as estatuetas esculpidas de Sátiros e Silenos, objetos comuns da religião grega, revelavam em seus interiores imagens de deuses quando eram abertas. A mesma coisa acontece com Sócrates: embora ele ostente uma aparência grotesca, desde que nos voltemos para seu interior (para sua alma), poderíamos encontrar ali dentro as mais autênticas e mais belas imagens da virtude. Hadot explora a comparação feita por Alcibíades para aprofundar uma ideia central em sua abordagem, a de que Sócrates se tornou “o prosopon, a máscara, de personalidades que tiveram necessidade de se proteger atrás dele" (2012, p. 10-11).

Entre estas personalidades que falaram através da máscara socrática, poderíamos encontrar a de Platão, pelo fato de nunca ter escrito em nome próprio e por ter usado Sócrates para dirigir seus diálogos, os quais, com efeito, seriam eivados de uma forte ironia dissimuladora, tal como ocorre com a personagem mais elusiva deles.

Depois, segundo Hadot, podemos encontrar Nietzsche, cultor de um verdadeiro "ódio amoroso" com relação a Sócrates, de quem denunciou o caráter "dis-

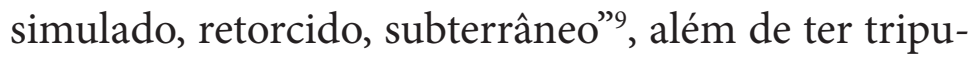
diado com a fisionomia desse homem e com o dilema que ela representava para alguém que viria a ser eleito como modelo de virtude por toda uma tradição

\section{archai圈}

n ${ }^{\circ}$ 18, sept.-dec. 2016

G. M. Almeida Júnior, 'Atopia em Pierre Hadot', p. 347-386 


\section{archai圈}

no 18 , sept.-dec. 2016

G. M. Almeida Júnior, 'Atopia em Pierre Hadot', p. 347-386 (apud Hadot, 2012, p. 10). Nem por isso, contudo, Nietzsche deixou de assumir uma estranha e ambígua proximidade com Sócrates. Segundo Hadot (2012, p. 16), Nietzsche "[...] ama e inveja em Sócrates o que ele gostaria de ser, o sedutor, o educador, o condutor de almas". Entre outras referências, Hadot cita ainda o conhecido fragmento do verão de $1875^{10}$, em que Nietzsche diz, a título de confissão, que ele se assemelha tanto a Sócrates que quase sempre se vê em luta com ele (apud Hadot, 2012, p. 10).

Em terceiro lugar, Hadot evoca Kierkegaard, que viu em sua própria tarefa de pensador uma "tarefa socrática": "Ô Sócrates!... Tua aventura é a minha". "Eu estou só. Minha única analogia é Sócrates. Minha tarefa é uma tarefa socrática" (apud HADOT, 2012, p. 14) ${ }^{11}$. Kierkegaard fez da ironia de Sócrates uma máscara para a comunicação da experiência da existência, a qual só poderia ser uma experiência de "comunicação indireta" (HADOT, 2012, p. 14). Sócrates teria descoberto a categoria do "Indivíduo" (2012, p. 24-25), sendo por isso tomado pelo pensador dinamarquês como uma espécie de duplo, pois tal como o pai da categoria central da existência era um ignorante que conseguia fazer os outros perceberem que eram ainda mais ignorantes do que ele, Kierkegaard sente a exasperação que ele impinge aos outros homens, porque pode admitir que não é um cristão, e por isso mesmo pode mostrar como os outros são ainda menos cristãos do que ele. Do mesmo modo que Sócrates não ensina, mas ironiza e seduz, Kierkegaard assume que não seria possível comunicar ou ensinar a responsabilidade da existência a outrem, daí seu apelo às máscaras, seja pela escrita pseudonímica, ambígua e sedutora, seja pelo recurso à banalidade e a recusa 
da posição de mestre, enfim, pela ironia que o pensador dinamarquês envida, segundo descreve Hadot.

Já a máscara de "Eros", tratada nas páginas 26-39 do Elogio de Sócrates, surge da identificação entre Eros e Sócrates que podemos "adivinhar" no discurso de Alcibíades no Banquete (Hadot, 2012, p. 30). Essa máscara erótica demonstra as ambiguidades de um ser ao mesmo tempo pleno de recursos e carente, de um intermediário entre os deuses e os homens, de alguém que se devota a amar uma plenitude que não será capaz de atingir, pois a sophia é um estado estranho à condição humana, como já vimos antes. Alcibíades assimila Sócrates a Eros, o daimon do amor, que vive uma situação "desconfortável” por ser um "intermediário", e é "indefinível e inclassificável, como Sócrates, o atopos" (Hadot, 2012, p. 34).

Podemos observar aqui também mais um aspecto da dissimulação de Sócrates em sua faceta erótica, pois Hadot nota que, segundo Alcibíades, Sócrates finge estar enamorado dos jovens belos, mas, de acordo com as inversões próprias de suas atitudes irônicas, subverte os papéis estabelecidos, tornando-se no processo de sedução o eromenos (amado), ao invés de o erastes (amante), como seria de se esperar.

Na seção "Dioniso", tratada nas páginas 39-48, Hadot evoca os traços dionisíacos de Sócrates também indicados por Alcibíades em seu discurso no Banquete para detalhar a complexa relação que Nietzsche estabelece com Sócrates. Essa relação, como foi dito, seria caracterizada por um "ódio amoroso", segundo uma expressão de E. Bertram ${ }^{12}$, que poderia definir com acuidade a complexidade dos laços entre o filó-

\section{archai蒡}

no 18 , sept.-dec. 2016

G. M. Almeida Júnior, 'Atopia em Pierre Hadot', p. 347-386 


\section{archai圈}

no 18 , sept.-dec. 2016

G. M. Almeida Júnior, 'Atopia em Pierre Hadot', p. 347-386 sofo de Basileia e o filósofo de Atenas. Hadot (2012, p. 44) comenta como Nietzsche supõe ter revelado o segredo de Sócrates, o de um pessimista que detesta a existência, que considera a vida como uma espécie de doença, da qual ele se sente libertado no momento da morte. Na linha de E. Bertram, Hadot sugere ainda que, no fim das contas, Nietzsche acaba vendo em Sócrates a própria figura de Dioniso, mesmo que de maneira inconsciente.

Ainda seguindo Hadot, nessa tergiversação de papéis e troca de máscaras, diretamente vinculada ao caso Sócrates, temos um complexo fenômeno de profundas implicações "literárias, pedagógicas e psicológicas" (2012, p. 11), em que Sócrates se oculta para a História, oferecendo um perfeito exemplo da dissimulação e ironia que ele pratica como método, enquanto, por outro lado, termina por revelar com toda a clareza possível a filosofia como uma prática caracterizada pela transformação de si e pelo cultivo da própria personalidade. No caso de Platão, esse jogo irônico encontra seu termo ou se desenvolve plenamente quando atinge os próprios leitores dos diálogos, os quais, tal como os interlocutores de Sócrates, são levados a questionar seus saberes e suas vidas de maneira integral.

Nesse sentido, Hadot sugere que por detrás das máscaras postas em Sócrates poderíamos encontrar ainda as máscaras daqueles que as colocaram, sejam as de Platão, as de Kierkegaard ou as de Nietzsche, assim como as nossas próprias. Bem entendido, o encontro com Sócrates, marcado pelo choque da aporia e da refutação, abre a possibilidade para que nos tornemos 'Sócrates' no processo de interrogação, ou, 
como afirma Hadot, no fim das contas, esse encontro extraordinário nos leva a procurar refúgio sob a máscara socrática, tal como sugere K. Gaiser ${ }^{13}$ :

A máscara, o prosopon, de Sócrates, desconcertante e inatingível, introduz uma perturbação na alma do leitor e a conduz a uma tomada de consciência que pode ir até à conversão filosófica. Como bem mostrou K. Gaiser, o próprio leitor é convidado a se refugiar atrás da máscara socrática (HADOT, 2012, p. 11).

A referência à obra de Gaiser não é fortuita, e sua importância transparece na análise que Hadot faz de Sócrates, isto é, o dos diálogos platônicos, os quais devem ser entendidos também como uma experiência de "comunicação indireta", fundada na erótica e irônica relação entre mestre/aluno, na relação entre ignorância e saber (ou no reconhecimento da ignorância), no teatro das personagens (já que Platão nunca fala em nome de seu "Eu"), e na compreensão de que os diálogos, mais do que construírem e apresentarem um sistema doutrinário fechado e acabado, antes promovem uma espécie de jogo irônico no qual os leitores são envolvidos. Os escritos platônicos, embora sejam imitações "duplamente enfraquecidas" do que teriam sido as provocativas conversações socráticas (Hadot, 2012, p. 18), dão a ilusão aos leitores de que eles participam das discussões das obras, e assim como as personagens que se deparam com Sócrates são conduzidas a tomar consciência de si como indivíduos, como problemas para elas mesmas, não sem uma profunda perturbação, isto também ocorre com os leitores dos diálogos, ou seja, também ocorre connosco ${ }^{14}$.

\section{archai葶}

n ${ }^{\circ}$ 18, sept.-dec. 2016

G. M. Almeida Júnior, 'Atopia em Pierre Hadot', p. 347-386 


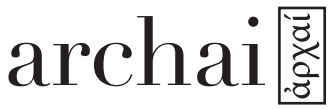

no 18 , sept.-dec. 2016

G. M. Almeida Júnior, 'Atopia em Pierre Hadot', p. 347-386

\section{4}

Não podemos neste contexto detalhar o juízo de Hadot acerca da escrita dialógica de Platão, um tema tão importante quanto ambíguo na obra do autor francês, pelo menos no Elogio de Sócrates, em particular quando procuramos mensurar o grau de adesão de Hadot ao denominado paradigma esotérico de interpretação da filosofia platônica. Ainda assim, em síntese, no que concerne à questão de como ler um diálogo platônico, Hadot retoma a posição de Gaiser de que as obras escritas não são autossuficientes, posto que, antes de qualquer coisa, elas seriam definidas pela protrepsis e parenesis, ou seja, pela "exortação" e pelo "encorajamento" à prática da filosofia (Hadot, 2012, p. 11-12). Os diálogos platônicos, determinados pela ironia e pelo jogo de máscaras entre Platão, o autor dos diálogos, Sócrates e as demais personagens, além dos leitores das obras, apontariam para as limitações do discurso escrito e para a constatação de que a filosofia pode ser encontrada mais propriamente na transformação individual (para não dizer pessoal) a que os diálogos exortam.

$O$ viés aludido no parágrafo anterior distingue o interesse de Hadot pelo ensinamento oral de Platão do núcleo das agrapha dogmata concebido pela escola de Tübingen-Milão, que possui um caráter rigorosamente sistemático e doutrinário, derivado de uma teoria dos princípios deduzida a partir de uma tradição indireta e exterior às obras escritas de Platão. Como podemos ver num texto posterior de Hadot (2008), que prefacia o livro de sua aluna M.-D. Richard (1986), por sua vez a responsável por ter introduzido a teoria dos princípios da escola de Tübingen-Milão na França, ainda que Hadot admita os méritos e a necessidade de prestarmos atenção à interpretação da referida 
escola, sobretudo em relação ao questionamento que ela teria aberto sobre a significação última da "forma" do diálogo platônico, o autor francês defende a possibilidade de pensarmos na sobrevivência da "aporética socrática" ainda nesse presumido ensinamento não escrito de Platão (Hadot, 2008, p. 19).

Hadot enfatiza aqueles aspectos da filosofia socrática bem conhecidos através de algumas imagens célebres que Platão desenvolve em seus diálogos, sobretudo no Banquete, e também na Apologia, onde Sócrates aparece como o questionador incansável que se furta a responder a questões, que admite a própria ignorância e compara a si mesmo a uma mutuca irritante que não cessa de lancinar o povo de Atenas, a fim de que seus concidadãos tomem consciência deles próprios, que eles cuidem deles mesmos, e não de coisas externas àquilo que os tornam indivíduos.

A partir de um cruzamento de elementos provenientes dos diálogos platônicos com elementos das apropriações de Sócrates por Kierkegaard e Nietzsche, Hadot procura mostrar que Sócrates não tem nada para ensinar, que sua filosofia na verdade corresponde à ironia, entendida como um processo de mascaramento e inversão que ao mesmo tempo oculta e revela o (não) saber e o caráter de alguém, enquanto Sócrates, o provocador desse jogo, continua encoberto. A ironia socrática se manifesta para além do discurso, em relações profundamente marcadas pelas emoções e pelo erotismo, o que frequentemente leva a linguagem a seus limites, conformados à própria experiência que ela procura expressar, sem sucesso pleno, a experiência da existência. Hadot afirma: "por esse apelo ao ser do indivíduo, a trajetória socrática

\section{archai周}

n 18 , sept.-dec. 2016

G. M. Almeida Júnior, 'Atopia em Pierre Hadot', p. 347-386 


\section{archai圈}

no 18 , sept.-dec. 2016

G. M. Almeida Júnior, 'Atopia em Pierre Hadot', p. 347-386 é existencial" (2012, p. 22). Enraizado nessa trajetória, Sócrates não doutrina ninguém, mas promove seu "despertar de consciência, ascensão a um nível de ser que só podem se realizar em uma relação de pessoa para pessoa" (2012, p. 36).

Dessa maneira, o que sobressai na complexa figuração de Sócrates por Hadot é uma leitura particular da ironia enquanto dissimulação e fingimento que culmina na protrepsis e parenesis, a exortação e o encorajamento à filosofia como uma maneira de viver. Hadot desenvolve o ceticismo historiográfico sobre Sócrates de uma maneira que poderíamos chamar de irônica, na medida em que observamos na leitura do intelectual francês uma estranha conjunção entre dissimulação e verdade. Não poderíamos encontrar a "pessoa" de Sócrates por detrás da "personagem", mas se essa verdade nos é negada, uma outra nos é concedida: compreender Sócrates seria precisamente mascarar-se sob o prosopon socrático, transformar-se em Sócrates, e assim, a partir das experiências perturbadoras e angustiantes da ironia, do diálogo, de Eros e da maiêutica, tomar consciência de si e transformar-se em outro ser. Hadot sugere que essa transformação do modo de vida é o sentido fundamental do jogo das máscaras socráticas, e que, por isso mesmo, Sócrates, além de irônico, seria atopos, ou seja, estranho, inclassificável e até mesmo absurdo, tal como veremos abaixo.

\subsection{ATOPIA E PERSONALIDAdE}

Apesar da rica figuração na qual o Sócrates de Hadot é envolto, a imagem proposta pelo autor francês claramente privilegia a versão platônica e em princípio não foge muito às discussões mais frequentes nos es- 
tudos críticos sobre o socratismo na forma que ainda hoje eles assumem, cujos delineamentos foram estabelecidos a partir da primeira metade do século XIX, com as obras de F. Schleiermacher (1818) e G. W. Hegel (1836), segundo G. Medrano (2004, p. 230-233).

Em que pesem as divergências e as múltiplas abordagens possíveis no campo dos estudos sobre Sócrates, boa parte delas devido às dificuldades históricas da questão das fontes de um filósofo que não teria deixado qualquer registro escrito próprio, alguns temas sobressaíram em se tratando de conceber os traços mais característicos da filosofia socrática, tais como as noções de maiêutica, interrogação, refutação, aporia, daimon, além do famigerado conceito de ironia, essencial para Hadot, como vimos no tópico anterior. Todavia, devemos pôr em relevo também a noção de "personalidade", que é igualmente crucial para o autor francês, ainda que não receba em sua obra o mesmo destaque conferido à análise das fontes e da significação da eironeia. Ainda que não tenhamos neste artigo a possibilidade de tratar com a profundidade devida a noção de "personalidade", uma questão que acompanha os estudos críticos sobre Sócrates desde seu surgimento, é preciso ter em mente o seguinte ponto, de certo modo compreensível no caso de um pensador ágrafo, que de alguma maneira fez da filosofia sua vida, a saber, de que a procura pela filosofia de Sócrates converge para a pergunta sobre "quem foi Sócrates?" e daí, segundo a expressão de muitos estudiosos, converge para a questão acerca da "personalidade" de Sócrates ${ }^{15}$.

Mesmo se com pouco ou nenhum esclarecimento acerca da noção de "personalidade" propriamente

\section{archai蒡}

n 18 , sept.-dec. 2016

G. M. Almeida Júnior, 'Atopia em Pierre Hadot', p. 347-386 


\section{archai圈}

no 18 , sept.-dec. 2016

\section{G. M. Almeida Júnior, 'Atopia em Pierre Ha- dot', p. 347-386}

dita, conhecidos estudiosos de Sócrates, seguindo variadas tendências teóricas, procuraram reconstituir a identidade socrática por detrás das máscaras que essa figura portou. A noção de "personalidade" tornou-se um tópico explícito e frequente em importantes estudos dedicados ao "problema de Sócrates", tais como, para citar alguns exemplos, os de E. Zeller (1931, p. 114-116), L. Robin (1938, p. 102), V. Magalhães-Vilhena (1984), F. Adorno (1986), G. Vlastos (1991), G. Medrano (2004), A. Stavru (2010), entre outros. O próprio Hadot destaca a questão da "personalidade" de Sócrates como o grande enigma em questão, acrescentando ainda mais uma referência aos estudiosos já enunciados, a de W. Jaeger ${ }^{16}$ :

Poder-se-ia dizer que Sócrates é o primeiro indivíduo da história do pensamento ocidental. Como bem sublinhou W. Jaeger, a literatura socrática, notadamente as obras de Platão e Xenofonte, buscando fazer o retrato literário de Sócrates, esforça-se por mostrar sua originalidade, sua unicidade. Esta necessidade nasce certamente da experiência extraordinária que representa o encontro com uma personalidade incomparável (HADOT, 2012, p. 26).

Se Hadot não foge tanto à regra dos estudiosos de Sócrates no que tange à ironia, por outro lado, seu tratamento da "personalidade incomparável" de Sócrates é incrementado por um tema originário da obra de Kierkegaard, pensador que, além de consolidar a relação fundamental entre Sócrates e a ironia como atitude existencial, foi um dos primeiros a notar a relevância filosófica de Platão ter classificado a principal personagem de seus diálogos como atopos, ou, mais precisamente, como atopotatos, a "mais singular das 
criaturas", tal como Kierkegaard entende a descrição de Sócrates no Teeteto (149a), e a reivindica para si (Kierkegaard, 1962, p. 13; 1986, p. 62) ${ }^{17}$. Para Hadot, como vimos, todo o "apelo ao ser do indivíduo" na origem da concepção da filosofia como maneira de viver era revelado por homens irônicos e sedutores tais como Sócrates e como Kierkegaard, e foi este último quem notou que Platão em seus diálogos não deixou de apontar o estranho caráter de seu mestre:

Está bem aí, como observou Kierkegaard, o sentido profundo das expressões atopos, atopia, atopotatos, que ressurgem muito seguidamente nos diálogos de Platão [Smp. 215 a; Phdr. 229-230; Alc. 1106 a] para descrever o caráter de Sócrates, por exemplo, no Teeteto (149 a): "Diz-se que eu sou atopotatos e que eu só crio a aporia". A palavra significa etimologicamente "fora de lugar", logo estranho, extravagante, absurdo, inclassificável,desconcertante. Em seu elogio de Sócrates no Banquete, Alcibíades insiste sobre esta particularidade (HADOT, 2012, p. 27).

Percebemos aqui o sentido da atopia socrática segundo Hadot. Ele responde ao problema da "unicidade" e da "originalidade" da "personalidade incomparável” de Sócrates. Sócrates é atopos para Hadot do mesmo modo que ele é o "Único" e o "Indivíduo" para Kierkegaard, e, na visão do filósofo e teólogo dinamarquês, ainda segundo Hadot, isto ocorre porque Sócrates, de maneira irônica, indireta e provocativa, conclama os homens a tomarem consciência de sua ignorância, de seu inacabamento e imperfeição, enfim, Sócrates os exorta a tomarem consciência da "seriedade da existência” (Hadot, 2012, p. 23-24). Numa en-

\section{archai蒡}

n 18 , sept.-dec. 2016

G. M. Almeida Júnior, 'Atopia em Pierre Hadot', p. 347-386 


\section{archai圈}

no 18 , sept.-dec. 2016

G. M. Almeida Júnior, 'Atopia em Pierre Hadot', p. 347-386 trevista concedida em 2001, Hadot sintetiza sua compreensão da apropriação de Sócrates por Kierkegaard:

Ele [o Sócrates de Kierkegaard] representa a seriedade da responsabilidade existencial do Indivíduo, do Existente, que é o Indivíduo e o Existente precisamente porque ele é estranho, inclassificável, dividido e dilacerado por sua incompletude ínsita, destituído de quem ele ama (HADOT, 2009, p. 123).

A decisiva referência a Kierkegaard no que concerne à atopia de Sócrates poderia ser explorada mais a fundo na obra de Hadot e por si mesma, embora isto exceda os limites deste artigo. Ainda assim, ressaltamos como Kierkegaard entende o atopotatos como a própria encarnação das noções de absurdo, paradoxo, individualidade e estrangeirismo ao mundo. Além disso, o Sócrates de Kierkegaard reflete também a aversão do pensador dinamarquês pelo conceito de "Sistema"18 que fulgurava na filosofia do século XIX, particularmente na de Hegel e na dos hegelianos, onde o indivíduo era subsumido pelo todo social e integrado ao espírito objetivo, na figura do "Estado", por oposição ao "Indivíduo" com "I" maiúsculo, o ser independente da sociedade, da cultura e da razão e solitário em sua consciência e responsabilidade existencial, que Kierkegaard procura salvaguardar.

Já em O que é filosofia antiga?, livro de 1995, Hadot volta ao tema da "personalidade única" de Sócrates, oferecendo mais elementos para discutirmos sua visão do homem capaz de "exercer uma espécie de fascínio e atração mágica”, e que, "apenas por sua presença, obriga aquele que se aproxima dele a pôr-se em questão" 
(HADOT, 2010, p. 56-57). Trata-se de uma abordagem mais superficial de alguns dos temas desenvolvidos no ensaio de 1974, que são repartidos entre o capítulo 3 ("A figura de Sócrates"), homônimo ao texto coligido em Exercices spirituels et philosophie antique, e o capítulo 4 ("A definição do filósofo no Banquete de Platão"); essencialmente, mais uma vez ambos os ensaios nos mostram Sócrates como o paradigma da filosofia como maneira de viver, e reiteram aqueles temas já destacados no tópico anterior deste artigo.

O mais importante aqui é a retomada da atopia de Sócrates por Hadot, novamente interpretada segundo o topos do Sócrates "inclassificável" e associada à visão que Kierkegaard faz de Sócrates como o "Indivíduo". Todavia, não seria equivocado ver na reflexão de Hadot ecos de outros pensadores franceses interessados nesse 'não-lugar' socrático, tais como J. Lacan (2001/1966-67), R. Barthes (1993/1977), além de Léon Robin (1938, p. 102), responsáveis por terem dado o tom da parca fortuna crítica que a atopia viria a suscitar posteriormente, embora Hadot não os mencione com relação à estranheza e originalidade de Sócrates.

Algumas diferenças sutis podem ser percebidas entre o Sócrates de O que é a filosofia antiga? e o Sócrates do ensaio de 1974. Um primeiro ponto a ser notado é que no livro de 1995 Hadot descreve um pouco melhor o fenômeno do socratismo e da fundação da prática filosófica como exercício espiritual em seu contexto de surgimento, situando o fenômeno de Sócrates em relação aos movimentos culturais, intelectuais e políticos do final do século $\mathrm{V}$ e primeiro quarto do século IV a. C., tendo por contraste os sofistas, os rétores e os outros socráticos, para além de

\section{archai蒡}

n ${ }^{\circ}$ 18, sept.-dec. 2016

G. M. Almeida Júnior, 'Atopia em Pierre Hadot', p. 347-386 


\section{archai圈}

no 18 , sept.-dec. 2016

G. M. Almeida Júnior, 'Atopia em Pierre Hadot', p. 347-386
Platão e Xenofonte. No entanto, desde que comparado aos principais movimentos intelectuais de sua época, uma vez mais Sócrates resulta singular, ou talvez mais singular ainda, de tal modo que o tema do filósofo incomparável e indefinível novamente vem à tona, e se o repetimos aqui é para ressaltar a ênfase que Hadot procura conferir ao assunto:

Mas Sócrates é impossível de classificar. Não se pode compará-lo a nenhum outro homem, quanto mais aos silenos e aos sátiros. Ele é atopos: estranho, extravagante, absurdo, inclassificável, desconcertante. No Teeteto, Sócrates dirá de si mesmo: "Eu sou totalmente esquisito (atopos) e não crio mais que aporia (perplexidade) [Tht.149a]. (HADOT, 2010, p. 57).

Ainda em O que é a filosofia antiga? Hadot se detém num aspecto muito caro à sua concepção dos exercícios espirituais, a relação entre o filósofo e a vida cotidiana, o que inclui os afazeres da cidade e o convívio com os outros homens na polis. Assim como a relação com o mundo dos homens era um problema para os filósofos antigos, torna-se um problema para Hadot pensar a respeito da possível conciliação entre uma filosofia definida pelo cuidado de si com uma espécie de "cuidado com os outros" (2010, p. 65-68). Esta rubrica intitula uma seção do livro de 1995, iniciada por Hadot com uma citação de M. Merleau-Ponty, que em sua aula inaugural no Collège de France, em 1953, constatou que a filosofia, sendo caracterizada pela ambiguidade e pela estranheza, "jamais está totalmente no mundo, e jamais, entretanto, fora do mundo", de um modo semelhante ao "estranho, o inclassificável Sócrates", como acrescenta Hadot (2010, p. 65) ${ }^{19}$. 
Nesse sentido, valendo-se da missão questionadora de Sócrates tal como descrita na Apologia de Platão, Hadot é levado a comentar a respeito da relação entre o cuidado de si socrático e o cuidado com os demais cidadãos e com a cidade como um todo:

Seus concidadãos não podem perceber seu convite para examinar seus valores, sua maneira de agir, para tomar cuidado consigo mesmo, como também para uma ruptura radical com a vida cotidiana, com os hábitos e as convenções da vida corrente com o mundo que lhes é familiar. Mas, de outro lado, esse convite para tomar cuidado consigo mesmo não será um apelo para afastar-se da cidade, vindo de um homem que está, de alguma maneira, fora do mundo, atopos, ou seja, que é estranho, inclassificável, absurdo? Sócrates não será o protótipo da imagem tão disseminada e, por outro lado, tão falsa do filósofo que foge das dificuldades da vida, para refugiar-se em sua boa consciência? (HADOT, 2010, p. 66).

Podemos notar no livro de 1995 alguns vestígios do diálogo aberto com Foucault nos anos 80, em que Hadot procurou consolidar os elementos de diferença entre sua própria visão dos exercícios espirituais e a visão de Foucault sobre a "estética da existência" ou "arte da vida", que teria uma ênfase mais estética e mais individualista, em contraponto a uma visão mais aberta para a alteridade, e, no caso específico da passagem antes citada de Hadot, mais voltada para a política, ou, mais corretamente, para o "cuidado com os outros", no sentido especial socrático (HADOT, 1987, p. 229-233). No entanto, para além de uma referência implícita a uma polêmica teórica, podemos ver como Hadot enfrenta em $O$ que é a filosofia antiga? uma aporia que com toda razão de ser emerge de suas próprias posições

\section{archai蒡}

$\mathrm{n}^{\circ} 18$, sept.-dec. 2016

G. M. Almeida Júnior, 'Atopia em Pierre Hadot', p. 347-386 


\section{archai圈}

no 18 , sept.-dec. 2016

G. M. Almeida Júnior, 'Atopia em Pierre Hadot', p. 347-386 em torno da estranheza de Sócrates e a estranheza do filósofo no mundo humano. Como vimos na citação acima destacada (2010, p. 66), o "cuidado de si" proposto por Sócrates não implicaria numa radical ruptura com a vida cotidiana, e o 'não-lugar' do filósofo não poderia sugerir (de maneira absurda) um topos fora do mundo? Não é precisamente esse um dos sentidos que a atopia assume, ao menos em parte, na Apologia de Platão, em que Sócrates tem que explicar moralmente sua participação e engajamento cívico, perante um tribunal popular, sob o risco da pena de morte?

Como reconhece Hadot, ser atopos, isto é, ser "estranho, inclassificável, absurdo", vem de par com uma sugerida negação ou abandono do mundo, e, por consequência, parece sugerir uma evasão da política ou do "cuidado com os outros", nos termos postos no livro de 1995. Nesta obra, a atopia é vista como passível de expressar o famigerado problema da fuga do filósofo do mundo dos homens, porquanto um atopos resiste à classificação e à ordem, repele o familiar, e parece estimular ou desafiar os outros homens a fazerem a mesma coisa.

Hadot mostra consciência de que a atopia pode manifestar um caráter não-político, ou mesmo um eventual caráter antipolítico (como uma espécie de desdobramento de seu caráter antimundano, por assim dizer $)^{20}$. Pois, se por um lado o que é inclassificável e desconcertante resiste a predicados e definições, por outro lado, como podemos ver nos discursos de Alcibíades, de Kierkegaard e Nietzsche, segundo Hadot, à atopia não se cessa de agregar máscaras, figuras e valores, sejam os do bem ou os do mal, seja algo mais matizado, ambíguo e mesmo contraditório do que

\section{4}


podem permitir os termos extremos de um espectro axiológico, o que justamente parece ser sugerido pela qualificação de Sócrates como atopos ${ }^{21}$. De qualquer maneira, é preciso levar em consideração que a atopia não é objeto de um elogio puro, nem mesmo no discurso de Alcibíades, como Hadot reconhece, logo no início do Elogio de Sócrates, admitindo que o discurso do enfant terrible de Atenas nem sequer se parece com qualquer encômio, pois contraria a expectativa básica de apresentar qualidades admiráveis de seu objeto; a atopia também motiva kategoriai, acusações, ela pode reforçar a suspeita sobre a "indecência" do comportamento filosófico perante os outros homens. No prefácio ao livro de J. Domanski, Hadot confirma essa impressão, ao notar que "quem vive de maneira filosófica é atopos, inclassificável", e que isso é refletido pela "personalidade do filósofo, estranha e estrangeira, talvez indecente aos olhos de seus concidadãos" (Hadot, 1996, p. XII).

Note-se ainda que no corpus platonicum e na língua grega antiga os adjetivos atopos (masculino) e atopon (neutro) possuem nuanças de sentido que podem lhes dar um tom neutro, passando por um tom eufemístico, até chegar a um claro tom depreciativo e derrogatório (Suda a. 4734; Arnott, 1964, p. 119-123). Platão não deixa de apresentar todo esse espectro semântico em sua obra, onde atopon, além de significar "inclassificável", muitas vezes designa algo "absurdo", "contraditório", "extraordinário", "impossível", e, às vezes, até mesmo aquilo que é simplesmente "ruim", entre outros sentidos (EIDE, 1996). É estranho perceber que Platão, do mesmo modo que reconhece e aceita a atopia socrática, não deixa de apontar também, para citar alguns exemplos, como são "atopous" os sofistas, que se

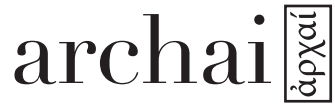

no 18 , sept.-dec. 2016

G. M. Almeida Júnior, 'Atopia em Pierre Hadot', p. 347-386 


\section{$\operatorname{archai}$}

no 18 , sept.-dec. 2016

G. M. Almeida Júnior, 'Atopia em Pierre Hadot', p. 347-386 dizem mestres de virtude (Grg. 519c4; 519d5), e como são "atopa" as explicações de Anaxágoras sobre a causalidade (Phd. 98c2), enfim, não deixa de descobrir e/ou produzir o absurdo de outras posições diante das quais erguer-se-iam as (presumidas) posições platônicas.

Nesse sentido, apontamos para um problema concernente ao valor da atopia- justamente por (tentar) expressar o "inclassificável", não haveria a abertura para a atopia também ser entendida e valorada como algo de ruim ou de pernicioso? Para voltar ao texto antes evocado por Hadot, o Elogio da Filosofia, de Merleau-Ponty (1953, p. 12), se pudermos distinguir, tal como este último, entre "uma má e uma boa ambiguidade" ("une mauvaise et une bonne ambiguité") da filosofia, diríamos que Hadot tende para a "boa ambiguidade" quando analisa o cuidado de si socrático em sua relação com a polis, seus concidadãos e habitantes, na medida em que Hadot reconhece a radical ruptura entre a filosofia e a vida cotidiana, ao mesmo tempo em que procura negar o topos ainda vigente na tradição ocidental acerca do filósofo que negligencia e despreza os assuntos mundanos, quando não simplesmente os ameaça e degrada.

Hadot declara como "falsa" (2010, p. 66) a imagem da filosofia que vira as costas ao mundo dos homens, bem como procura rechaçar a imagem do filósofo que se consolidou em certas tradições históricas como um ser alienado e/ou perigoso, e que também teria sua origem no caso de Sócrates, para vermos que alguém tido como arredio a todas as classificações e categorizações, tal como o Sócrates atopos, em alguma medida, pode recebê-las todas, o que, por certo, é bastante estranho e paradoxal.

\section{6}


Hadot põe uma questão trinchante para Sócrates e Platão, e também para si mesmo, mas opta por uma solução um tanto quanto simplificadora para um problema que Sócrates enfrentou em sua vida (e que o levou à morte) e que Platão não cessou de encarar em seus diálogos, ao deixar claras as ambiguidades, aporias e contradições inerentes ao valor das práticas socráticas (em especial o seu valor político), e ao elaborar um complexo discurso filosófico sobre a definição de modos ou gêneros de vida, que viria a ter uma grande repercussão na tradição de pensamento ocidental, sobretudo no que concerne à perene tensão entre teoria e prática (ou entre vida teorética e vida prática). Ainda que Hadot reconheça a tensão, ele acaba por atenuar o conflito entre o modo de vida filosófico e a vida política em favor de uma breve consideração sobre o valor positivo das atitudes cívicas de Sócrates, como se este último representasse, paralelamente ao modelo do filósofo, o modelo do cidadão excelente. De certo modo, Hadot minimiza o fato de que Sócrates não apenas inaugura o sentido mais autêntico da philosophia, mas também, a partir disso, insinua um sentido totalmente extraordinário para a política. Assim, de maneira implícita, Hadot parece tender para o juízo de Xenofonte, formulado na Apologia, segundo o qual Sócrates evidentemente não era culpado das acusações que lhe foram atribuídas, que Sócrates abdica de se defender, e por isso é condenado à morte, à qual ele se entrega de bom grado, porque julga que morrer é menos indigno do que padecer dos dissabores da velhice.

Neste aspecto, cabe-nos notar, Foucault parece estar mais atento a certos problemas inerentes ao cuidado de si socrático em sua suposta relação intrínseca com

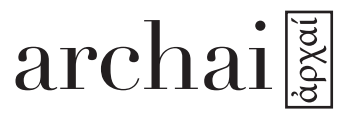

n 18 , sept.-dec. 2016

G. M. Almeida Júnior, 'Atopia em Pierre Hadot', p. 347-386 


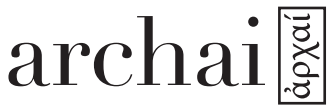

no 18 , sept.-dec. 2016

G. M. Almeida Júnior, 'Atopia em Pierre Hadot', p. 347-386 o "cuidado dos outros". Ao contrário de Hadot, no entanto, Foucault afirma que a controversa dimensão altruística da importante invenção de Sócrates não seria política ela mesma, mas constituída numa "relação com a política”, relação essa que seria "cara a cara” e de "contestação" (Foucault, 2008/1983, p. 313). Ademais, as práticas do governo de si e do governo dos outros seriam definidas pela parresia, o ato livre e arriscado de enunciação da verdade no qual se desenrola o processo de subjetivação ${ }^{22}$, cuja estrutura fundamental seria diametralmente oposta à dissimulação e ao jogo de máscaras provocado pela ironia socrática segundo a visão de Hadot. É verdade que Foucault parece ir longe demais quando sustenta que o ciclo da vida e da morte de Sócrates engendrou uma prática marcada por uma "especificidade não política" (Foucault, 2009/1984, p. 84), mas esse juízo serve para contrabalançar a tendência de Hadot no sentido oposto, já que este último atenua os choques e os perigos associados à dimensão (a)política da atopia socrática. Nesse aspecto, o contraste entre os pontos de vista de Hadot e os de Foucault nos alerta para a necessidade de resguardar o aspecto subversivo e absurdo da "estranheza" de Sócrates e da filosofia no mundo humano, em especial com relação à vida política.

Outros paradoxos podem surgir da análise de Hadot sobre a atopia socrática, em particular aqueles decorrentes dos persistentes impasses do tradicional "problema de Sócrates", dos quais Hadot procurou se desvencilhar, pelo menos de alguns deles, quando optou por concentrar seu interesse nos processos criativos em torno da figura de Sócrates ao invés de desvelar uma suposta realidade histórica escamoteada pelo mito. Não obstante, é preciso fazer jus ao fato de

\section{8}


que Hadot mostra plena consciência de que sua análise da atopia surge ela própria do paradoxo inerente às tentativas de compreender a originalidade socrática, que inevitavelmente recaem na contradição de ter que conformar o "atopos" numa classe. Hadot reconhece esse paradoxo, mas habilmente procura contorná-lo, pois para o autor francês não há uma verdade sobre a doutrina do Sócrates histórico, e mais que isso, nem poderia haver, já que não há uma teoria ou um discurso capaz de expressar de maneira adequada o significado da filosofia ou do modo de vida socrático, talvez com a única exceção daquilo que Sócrates aprende com Diotima, as coisas do amor. Entretanto, esse único saber, ou, mais exatamente, esse único "desejo", não representa pouca coisa, pois, segundo a perspectiva de Hadot, esse impulso determina o sentido da "philo-sophia" como o reconhecimento da própria ignorância e como uma busca erótica por um estado de plenitude divina, interpretação que serve de base para o autor francês na constituição de sua mais distintiva tese sobre a singularidade da filosofia antiga.

\section{Considerações finais}

Na primeira parte deste artigo, mostramos como surge na obra de Hadot a atopia, o conceito de "estranheza", que é evocado para dar conta de um tema comum nos estudos socráticos, o da personalidade incomparável de Sócrates, a partir do que aglutina outras significações e implicações. A atopia de Sócrates tal como visada por Hadot é submetida a uma particular concepção de ironia como dissimulação, cuja significação e processo descrevemos neste texto, mostrando suas origens e alguns de seus impasses pontuais. Com a atopia, Hadot reelabora de maneira peculiar um co-

\section{archai圈}

n 18 , sept.-dec. 2016

G. M. Almeida Júnior, 'Atopia em Pierre Hadot', p. 347-386 


\section{archai圈}

no 18 , sept.-dec. 2016

G. M. Almeida Júnior, 'Atopia em Pierre Hadot', p. 347-386 nhecido topos da tradição literária e filosófica, segundo o qual Sócrates é tido como o modelo maior de uma prática que, nas palavras do autor francês, é "inteiramente exercício espiritual, novo modo de vida, reflexão ativa, consciência viva" (Hadot, 2012, p. 24). O Sócrates "estranho" e "inclassificável” que emerge dos textos aqui analisados reforça e corresponde aos pressupostos de Hadot em torno de uma forte distinção entre "discurso filosófico" e "filosofia" (D.L. 7. 39; HADOT, 1987, p. 218; 2010, p. 249-258) e corrobora a tese do autor sobre o caráter especial da filosofia (antiga) como exercício espiritual, cuja essência é a transformação de todo o modo de ser daquele que a pratica, mais do que a formulação de doutrinas e sistemas de pensamento. Desse modo, podemos ver que o Sócrates de Hadot ganha nítidos contornos existencialistas e figura como o patrono e o arquétipo da concepção "personalista" de filosofia que o autor francês procura reavivar, em seus aspectos históricos, teoréticos e práticos.

Isto nos leva ao Elogio da Filosofia Antiga, ensaio no qual Hadot aprofundará sua visão da atopia, projetando a "estranheza" da personalidade de Sócrates na "estranheza" de todo o modo de vida filosófico dos antigos (HADOT, 2012b). Contudo, esse assunto será tratado na segunda parte deste artigo, na qual procuraremos verificar se e de que maneira a atopia socrática, que se refletiria na filosofia antiga de maneira geral, também seria de alguma maneira espelhada na obra de Pierre Hadot, e quais seriam as implicações disto para compreendermos e avaliarmos o pensamento do intelectual francês. 


\section{Notas}

1 Agradeço à professora Loraine F. Oliveira, bem como a José A. Ribeiro, Marcelo P. Marques e Flávio F. Loque pelo apoio na elaboração deste artigo. Os erros que subsistirem aqui são de minha responsabilidade.

2 Ver D.L. 2.20.

3 Cf. Gigon, O. (1945), Sokrates, sein Bild in Dichtung und Geschichte, Berna, Francke. Como se sabe, a obra de Gigon foi determinante para a consolidação do ceticismo em relação ao "Sócrates histórico" na segunda metade do século 20.

4 Ver Hadot (2009, p. 121-122). Ver ainda Nehamas (1998) e Cooper (2012), autores que também afirmaram o papel de Sócrates como o fundador da tradição da filosofia como "arte de viver" ou como "modo de vida", a partir de perspectivas divergentes das de Hadot.

5 Utilizamos aqui a tradução de Oliveira e Loque (Hadot, 2012).

6 Cf. E.N. $1108^{\text {a } 22 ; 1127 a 22 . ~}$

7 Cf. Caracteres 1.

8 Cf. Luculus 15; Brutus 292-300.

9 Cf. NIETZSCHE, F. O Crepúsculo dos Ídolos. O problema de Sócrates, $\$ 4$ (trad. NRF, t.VIII, p. 71).

10 Cf. F. P. 6. 3.

11 Cf. L'instant, $\$ 10$.

12 Cf. Bertram, E. (1985), Nietzsche. Versuch einer Mythologie, $9^{a}$ ed., Bonn. (trad. fr. R. Pitrou, Nietzsche. Essai de mytho-

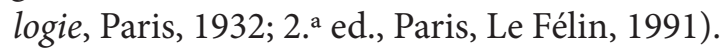

13 Cf. Gaiser, K. (1959), Protreptik und Paränese bei Platon. Untersuchungen zur Form des platonischen Dialogs. Stuttgart, Kohlhammer.

14 Ver ainda Hadot (2010, p. 113), onde o autor declara que o propósito dos diálogos platônicos é antes "formar" do que "informar", algo que mesmo o estruturalista V. Goldschmidt reconhecia.

\section{archai䀥}

$\mathrm{n}^{\circ}$ 18, sept.-dec. 2016

G. M. Almeida Júnior, 'Atopia em Pierre Hadot', p. 347-386 


\section{archai圈}

no 18 , sept.-dec. 2016
15 Aqui entendemos o conceito de "personalidade" de maneira provisória, tal como ele aparece recorrentemente nos estudos socráticos, mais ou menos como "modo de ser, de comportar-se e de lidar com os outros" (STAVRU, 2010, p. 25).

16 Cf. JAEGER, W. (1954), Paidéia, t. II, Berlin.

17 Entretanto, na tese sobre a ironia (KIERKEGAARD, 1991), a atopia não é explicitamente tratada.

18 Kierkegaard (1962, p. 3 et passim) - ou Climacus, no caso - grafa "Sistema" com a letra inicial maiúscula, tal como quando fala de "Indivíduo", ressaltando a oposição estrutural entre os dois conceitos em sua obra.

19 Numa entrevista em 2001, Hadot reitera a "grande admiração" que ele nutria pelo Elogio da Filosofia de Merleau-Ponty, no qual Sócrates era tomado como um "patrono" da atitude filosófica (HADOT, 2009, p. 121).

20 Hadot (2012, p.23, n.62) já havia notado, à luz do juízo de Hegel, que a ironia socrática torna-se dramática quando no fim das contas leva Sócrates à morte.

21 Já que parte dos significados expressos pelos adjetivos atopos-on e pelo substantivo atopia implica numa coexistência de contrários (MAKOWSKI, 1994; EIDE, 1996; BLONDELL, 2002, p.73, n.102).

22 Sócrates seria um campeão desse processo; Foucault (2009, p. 26) o denomina simplesmente de "o parresiasta". 


\section{BibliografiA}

ADORNO, F. (1986). Sócrates. Trad. J. A. Ribeiro Lisboa, Edições 70

ARNOTT, G. W. (1964). The Confrontation of Sostratos and Gorgias. Phoenix, Toronto, v.18, n.2, p. 110$-123$.

BARTHES, R. (1993). Fragmentos de un discurso amoroso. Trad. E. Molina. Madrid, Siglo Veintiuno.

BLONDELL, R. (2002). The Play of Character in Plato's Dialogues. Cambridge, Cambridge University Press.

BURNET, J. (1900-1907). Platonis opera, I-V, recognovit brevique adnotatione critica instrvxit Ioannes Burnet. Oxford, Clarendon Press.

COOPER, J. M. (2012). Pursuits of Wisdom: Six Ways of Life in Ancient Philosophy from Socrates to Plotinus. Princeton, Princeton University Press.

DAVIDSON, A. I. (2010). Entretien entre Pierre Hadot et Arnold I. Davidson, École normale supérieure, $1^{\text {er }}$ juin 2007. In: DAVIDSON, A. I.; WORMS, F. (eds.). Pierre Hadot, l'enseignement des antiques, l'enseignement des modernes. Paris, Éditions ENS Rue d'Ulm, p. 19-34.

DIOGENIS LAERTII (2008). Vitae philosophorum Vol. 1, libri I-IX. Edidit Miroslav Marcovich. Berlin, De Gruyter.

EIDE, T. (1996). On Socrates' atopia. Symbolae Osloenses: Norwegian journal of Greek and Latin studies, Oslo, v. 71, n.1, p.59-67.

\section{archai圈}

$n^{\text {o }} 18$, sept.-dec. 2016

G. M. Almeida Júnior, 'Atopia em Pierre Hadot', p. 347-386 


\section{$\operatorname{archai}$}

no 18 , sept.-dec. 2016

G. M. Almeida Júnior, 'Atopia em Pierre Hadot', p. 347-386
FOUCAULT, M. (2008). Le gouvernement de soi et des autres. Cours au Collège de France, 1982-1983. Paris, Gallimard/Le Seuil.

_(2009). Le courage de la vérité. Le gouvernement de soi et des autres II. Cours au Collège de France, 1983-1984. Paris, Gallimard/Le Seuil.

HADOT, P. (1987). Exercices spirituels et philosophie antique. Deuxième édition revue et augmentée. Paris, Études Augustiniennes.

_(1996). Préface. In: DOMANSKY. J., La philosophie: théorie ou manière de vivre? Les controverses de l'Antiquité à la Renaissance. Suisse/Paris, Editions Universitaires Fribourg/Éditions du Cerf, p. V-XIII.

_(2008). Prefazione. In: RICHARD, M. D. L'insegnamento orale di Platone: Raccolta delle testimoniaze antiche sulle "dottrine non scritte" con analisi e interpretazione. Vol. 1. Trad. G. Reale. Milano, Bompiani, p. 9-19.

_(2009). The present alone is our happiness: conversations with Jeannie Carlier et Arnold I. Davidson. Trad. M. Djaballah, Stanford, Stanford University Press.

_(2010). O que é a filosofia antiga? Trad. D. Macedo, São Paulo, Loyola.

_(2012). Elogio de Sócrates. Tradução de L. Oliveira; F. F. Loque, São Paulo, Edições Loyola.

_(2012b). Elogio da filosofia antiga. Tradução L. Oliveira, F. F. Loque. São Paulo, Edições Loyola. 
KIERKEGAARD, S. (Johannes Climacus). (1962). Fragments of philosophy or a fragment of philosophy. Originally translated and introduced by D. F. Swenson; new introduction and commentary by N. Thulstrup. Translation revised and commentary by H. V. Hong. Princeton, Princeton University Press.

_(1986). Ponto de vista explicativo de minha obra como escritor. Tradução J. Gama. Lisboa, Edições 70.

(1991). O conceito de ironia constantemente referido a Sócrates. Tradução de A. L. M. Valls. Petrópolis, Vozes.

LACAN, J. (2001). Le séminaire de Jacques Lacan. Livre VIII, Le transfert: 1960-1961. Texte établi par J.-A. Miller. Paris, Seuil.

MAGALHÃES-VILHENA, V. (1984). O problema de Sócrates: o Sócrates histórico e o Sócrates de Platão. Lisboa, Fundação Calouste Gulbenkian.

MAKOWSKI, F. (1994). Où est Socrate? Laporie de l'atopicité chez Platon. Revue de Philosophie Ancienne, Bruxelles, v. 12, n. 2, p. 131-152.

MEDRANO, G. L. (2004). Guía para no entender a Sócrates: Reconstrucción de la atopía socrática. Madrid, Trotta.

MERLEAU-PONTY, M. (1953). Éloge de la philosophie et autres essais. Paris, Gallimard.

NEHAMAS, A. (1998). The Art of Living: Socratic Reflections from Plato to Foucault. Berkeley, University of California Press.

\section{archai圈}

no 18 , sept.-dec. 2016

G. M. Almeida Júnior, 'Atopia em Pierre Hadot', p. 347-386 


\section{archai 䀥}

no 18 , sept.-dec. 2016

G. M. Almeida Júnior, 'Atopia em Pierre Hadot', p. 347-386
PINHEIRO, A.E. (2008). Xenofonte. Apologia/ Banquete (tradução, introdução e notas). Coimbra, Centro de Estudos Clássicos e Humanísticos.

ROBIN, L. (1938). Notice. In: Platon: Oeuvres complètes. Tome IV-Le Banquet. Texte établi et traduit par Léon Robin. Paris, Belles Lettres, p.VII-CXV.

SOUZA, J. C. (1970). Platão. O Banquete (tradução, introdução e notas). São Paulo, Difel.

SUDA. s.v. Atopias pleon pragma. Disponível em: <http://www.stoa.org/sol-bin/search. pl?db=REAL\&search_method=QUERY\&login $=$ gue st\&enlogin=guest\&user_list=LIST\&page_num $=1 \&$ s earchstr=alpha,4374\&field=adlerhw_gr\&num_per_ page $=1>$ Acessado em 28 de Setembro, 2015.

STAVRU, A. (2010). "The present state of socratic studies: an overview". In: STAVRU, A.; ROSSETI, L. (eds.). Socratica 2008. Studies in Ancient Socratic Literature. Bari, Levante, p.11-47.

TURNER, J. S. (1993). Atopia in Plato's Gorgias. International Studies in Philosophy, v.25, n.1, p.69-77.

VLASTOS, G. (1991). Socrates: ironist and moral philosopher. Ithaca/New York, Cornell University Press.

ZELLER, E. (1931). Outlines of history of Greek philosophy. 13a ed. revised by W. Nestlé and translated by L. R. Palmer. London, Routledge \& Kegan Paul.

Submetido em Julho e aprovado para a publicação em Agosto, 2015 